\title{
Article
}

\section{IT and the NHS: Investigating different perspectives of IT using soft systems methodology}

Gillies, Alan Cameron and Patel, Inderjit

Available at https://clok.uclan.ac.uk/6585/

Gillies, Alan Cameron and Patel, Inderjit (2009) IT and the NHS: Investigating different perspectives of IT using soft systems methodology. Studies in Ethics, Law, and Technology, 3 (2). ISSN 19416008

It is advisable to refer to the publisher's version if you intend to cite from the work. http://dx.doi.org/10.2202/1941-6008.1094

For more information about UCLan's research in this area go to http://www.uclan.ac.uk/researchgroups/ and search for < name of research Group>.

For information about Research generally at UCLan please go to http://www.uclan.ac.uk/research/

All outputs in CLoK are protected by Intellectual Property Rights law, including Copyright law. Copyright, IPR and Moral Rights for the works on this site are retained by the individual authors and/or other copyright owners. Terms and conditions for use of this material are defined in the policies page. 


\section{Studies in Ethics, Law, and Technology}

Volume 3, Issue $2009 \quad$ Article 10

\section{IT and the NHS: Investigating Different Perspectives of IT using Soft Systems Methodology}
Alan C. Gillies, University of Central Lancashire Inderjit Patel, University of Central Lancashire

Recommended Citation:

Gillies, Alan C. and Patel, Inderjit (2009) "IT and the NHS: Investigating Different Perspectives of IT using Soft Systems Methodology," Studies in Ethics, Law, and Technology: Vol. 3: Iss. 2, Article 10.

DOI: $10.2202 / 1941-6008.1094$ 


\title{
IT and the NHS: Investigating Different Perspectives of IT using Soft Systems Methodology
}

\author{
Alan C. Gillies and Inderjit Patel
}

\begin{abstract}
The UK NHS National Programme for IT has been criticized for a lack of clinical engagement. This paper uses a soft systems methodology (SSM) analysis of a case study from the use of electronic systems within a National Health Service (NHS) Mental Health Trust in the United Kingdom (UK) to explore the legal and ethical implications of the failure to develop clinical systems which are fit for purpose.

Soft systems methodology (SSM) was used as a theoretical model both to derive deeper insights into the survey data and suggest how communication between those producing information and those using it, could be improved. Multiple methods were employed which included a postal survey and participant interviews to triangulate the data .

The use of SSM reinforced the concept that the national IT programme is based on a 'hard' systems view and does not take local factors (which are related to 'soft systems' thinking) into account. The study found administrative staff to be a crucial link between clinicians and information departments and highlighted the need for a joint-up information strategy and integrated systems.

The article concludes with a discussion of the legal and ethical implications of the findings and the lessons for the broader UK national programme. It argues that the failure to deliver systems that are fit for purpose is not value neutral but an ethical issue.
\end{abstract}

KEYWORDS: ethics of health information systems, mental health information technology, information systems, clinical engagement 
Gillies and Patel: IT and the NHS

\section{Introduction}

The National Programme for IT in the National Health Service (NPfIT), delivered by NHS Connecting for Health (NHS CfH), was set up to provide modern IT services for the NHS in response to the Wanless reports (Wanless (2002), using centrally managed procurement to provide impetus to the uptake of IT and to secure economies of scale. It constitutes the largest single IT investment in the UK to date, with expenditure on the Programme expected to be $£ 12.4$ billion over ten years to 2013-14. (House of Commons Committee of Public Accounts, 2007).

The central component of the Programme is the NHS Care Records Service (NHS CRS), which is designed to replace local NHS computer systems with more modern integrated systems and make key elements of a patient's clinical record available electronically throughout England (e.g. NHS number, date of birth, name and address, allergies, adverse drug reactions and major treatments) so that it can be shared by all those needing to use it in the patient's care. The Programme also includes other services, such as electronic prescriptions, an email and directory service for all NHS staff (NHSmail), computer accessible X-rays (Picture Archiving Communication Systems), and a facility for patients to book outpatient appointments electronically (Choose and Book).

In spite of the significant investment, the biggest problem with the current project is that it fails to engage clinicians, who perceive their own record keeping to be a paper-based activity, and electronic records to be a management tool which represents a work overhead with little immediate benefit to the clinicians or their patients. UK National Audit Office (2006); Coiera (2007)

This failure to engage clinicians has also been seen elsewhere in Europe, for example in Gillies and Howard's recent work for the Czech Government Gillies and Howard (2008) on behalf of the European Commission.

Typically, electronic patient records systems have been enthusiastically embraced by early adopters but failed to achieve widespread acceptance amongst the medical profession as a whole. Where they have achieved engagement by the vast majority it is in sectors and contexts where there is a direct financial incentive eg UK general practice (Gillies, 2008).

This article focuses instead upon the ethical and legal implications of the failure to engage clinicians and the consequent failure to impact upon patient care.

Traditionally, ethical debate around the implementation of very large electronic patient record systems has focused around privacy (see, for example, Williams (2005)). However, this is not surprising when we consider some elements of the existing data protection framework that exist in the medical setting. Beginning with the Hippocratic Oath we see the concept of dataprotection is enshrined in medical profession: 
"What I may see or hear in the course of the treatment or even outside of the treatment in regard to the life of men, which on no account one must spread abroad, I will keep to myself, holding such things shameful to be spoken about." (Edelstein, 1943)

Or in a more modern version due to Lasagna (1964):

"I will respect the privacy of my patients, for their problems are not disclosed to me that the world may know."

This version recognises that a key data protection requirement is to ensure that the purpose for information sharing is appropriate

In the modern context, under the European Union's Data Protection Directive (95/46/EC) Health information has special protection as it can be said to be 'sensitive personal data'. As a result certain restrictions apply to the way in which data is used.

Within the UK, the implementation of the directive requires all holders of personal data to operate within eight data protection principles. Data must be:

- Fairly and lawfully processed

- Processed for limited purposes

- Adequate, relevant and not excessive

- Accurate and up to date

- Not kept for longer than is necessary

- Processed in line with your rights

- Secure

- Not transferred to other countries without adequate protection

However, there is a need to move policy discussions on the subject of electronic patient records away from concerns about the potential misuse of the data, and an exploration of privacy/data protection concerns towards a broad spectrum ethical evaluation of the potential value of electronic records perceived through the lens of patient safety. This necessitates a departure from the standard polarisation of discussions around privacy and data protection, and a move towards a wider discussion of risk and benefits relating to the systems themselves.

There is a paucity of good empirical studies of the role of information and records within real world clinical environments. Therefore the starting point for the exploration is a case study to illustrate the current situation.

\section{Background to the case study}

The case study explores the role of information in an NHS mental health trust in the UK. Using clinical information to support clinical practice has not traditionally been a priority for practitioners in mental health trusts in the UK (Goddard et al, 2001). This study analyses data requirements and highlights gaps in data provision as well as exploring how practitioners can be best supported. 
The opinions and views of a wide range of end users were explored using questionnaires and interviews in order to obtain a "big picture" or holistic view of data and information flows. Ultimately the ways in which communication between practitioners and information staff may be improved were investigated.

Current systems being used in the mental health trust are varied and disparate, making it difficult for clinicians to obtain a complete picture of their clients care pathway. The requests for information from corporate personnel often take priority over requests made by clinicians, due to the direct financial implications. Clinicians are often informed that the information they require is not available, as systems are not linked together. The value of information in the Trust as a consequence has been relatively poor.

\section{The methodological approach adopted}

A combined methodological approach or triangulation (Morgan, 1998) was employed in this research, which included a documentation review, survey and participant interviews. This study adopts an interpretive approach, in that it attempts to understand phenomena through the meanings that people assign to them and recognises that issue has many viewpoints relating to it, as Walsham (1993) describes. This study uses Soft Systems Methodology (SSM) because it accepts there are multiple viewpoints relating to a specific issue and enables a problem domain to be dissected into its constituent parts.

\section{Data collection}

The first stage of data collection was a literature review structured around the problem, context and methodology and revealed the following themes:

- Lack of access to information/advice hinders successful management of cases (Fakhoury \& Wright 2000, Pollock et al 2004);

- Standards are necessary to measure performance and progress, which promotes improvements (Donabedian 1988, Rea \& Rea 2002);

- There is a need for joint-up care and I.T. systems (Warner \& Hoadley 2004, Rees et al 2004);

- To analyse an organisation holistically, many viewpoints need to be explored and communicated (Wells 1995, Stokes \& Lewin 2003);

- Soft Systems Methodology (Checkland 1981) accepts there are multiple viewpoints in a given situation and has been employed successfully in the NHS (Summers 2006).

The primary data collection used a combination of a questionnaire and semi-structured interviews. The questionnaire was to provide the bulk of primary data, therefore, it was felt that its design should be as robust as possible. The 
questionnaire was piloted with a small group of staff in the Trust. Comments and ideas received from the pilot, were fed back into the design process. Comments received related to the phrasing of some questions, as well as the general design of the questionnaire.

The pilot questionnaire comprised of twelve questions, based upon the Likert scale. Ten pilot questionnaires were distributed with an accompanying letter. The final questionnaire was refined with feedback from the pilot. The final questionnaire comprised seventeen questions, requiring ticked responses from the Likert scale, as in the pilot questionnaire. Space for additional comments was provided. The main survey sample was selected by the use of gatekeepers, which were highlighted by the R\&D co-ordinator. The study was marketed to them by emphasising how the research findings could be used to benefit their teams.

The number of questionnaires sent was 280 . The response rate was 73 , which represents $26 \%$ of the total distributed.

The data from the questionnaires was then triangulated through a series of semi structured interviews in the following manner. The ten staff groups used in the questionnaire were grouped into 'practitioner' and 'non-practitioner'. The questionnaire responses were analysed by these two groups, from which, two separate rich pictures were constructed to provide an unstructured description of the problem in the manner of the first two stages of SSM, described below.

Responses from the survey centred around the following functions in the organisation:

- Information Management \& Technology (IM\&T);

- Services;

- Communications network.

From the analysed questionnaires, the following major themes emerged:

- Communication and information flows between services and the IM\&T department;

- Activities that data is currently used for;

- How staff can be encouraged to use data more within their services.

The two rich pictures were constructed around these themes and the relationships between them.

Practitioners and non-practitioners who agreed to be interviewed were sent the rich-picture derived from their constituency and a list of questions prior to being interviewed.

Two interviews were conducted face-to-face and four were conducted over the telephone. This was due to the wide geographical spread of services and the availability of staff who agreed to be interviewed. The six interviews conducted are immediately transcribed by the researcher.

The data derived from this process was analysed using the Soft Systems Methodology (SSM). 


\section{Data analysis: An overview of SSM}

SSM attempts to understand a given organisation holistically by analysing the structure of organisations as a whole and from many viewpoints. Checkland and Scholes (1990) have applied this methodology at the community level in the NHS, where they developed models of a system that could evaluate any health care project. They based this on the idea that health is a changing "norm" rather than an attainable goal. The methodology contains:

- real world activities which involve people in the problem domain, and

- systems thinking activities that may or may not involve those in the problem domain.

The traditional SSM model is organised into seven distinct stages, which are summarised in Figure 1.

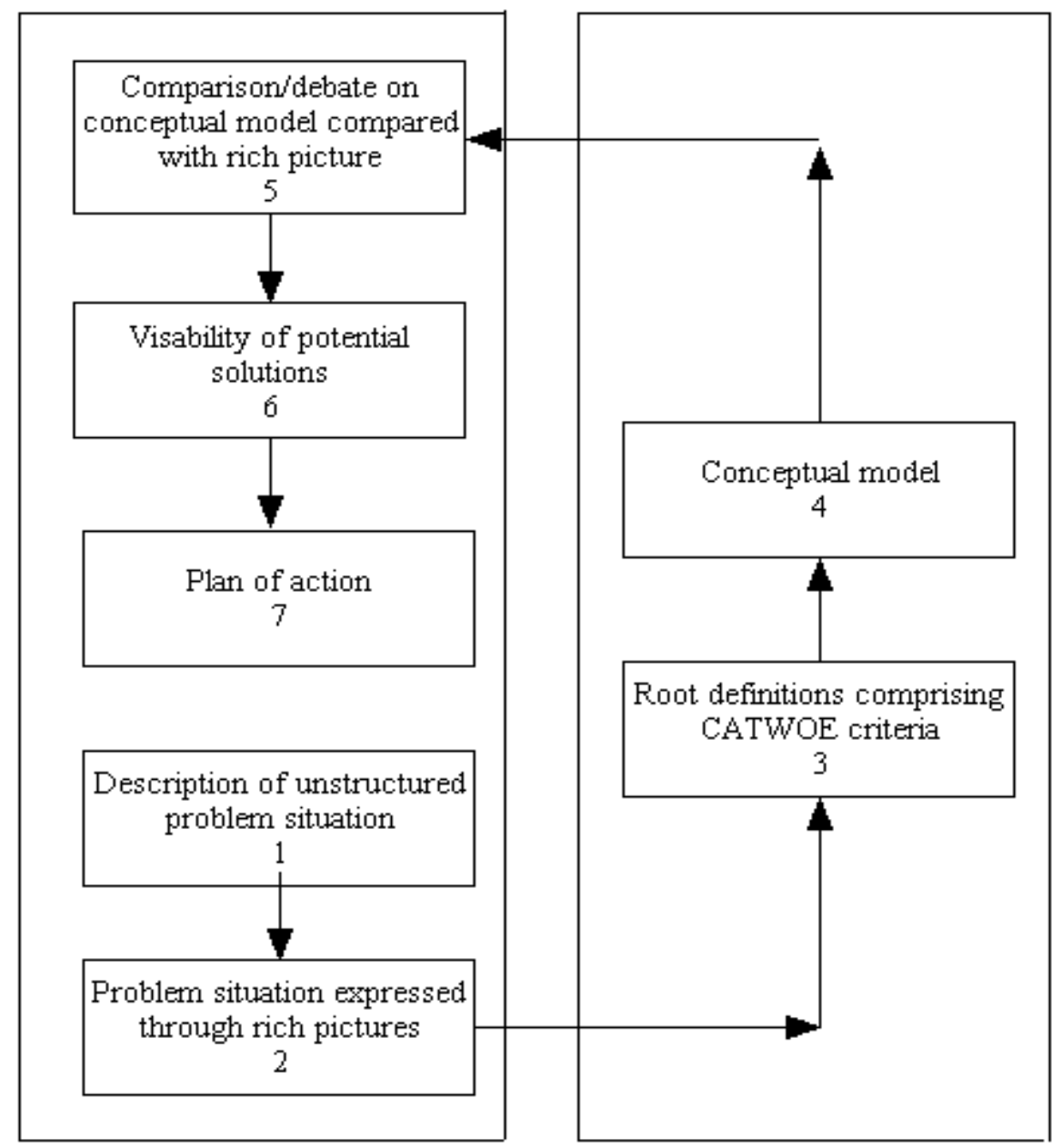

Figure 1. Stages of SSM, adapted from Macias-Chapula (1992) 


\section{Reasons for using SSM}

SSM offers a flexible approach which allows the author to tailor its individual stages to the specific project objectives and is used for analysing systems that have significant technological and human dimensions.

SSM has been used in many public sector projects for which it has been designed, specifically in the NHS. For example, Bolton (1987) used SSM when he investigated the move from institutional mental health services to community care. He suggests that a soft systems approach can help untangle the changes required in structures, practices and values, as it is most useful where human factors dominate. Mental health care is often unclear and does not necessarily fit into the 'hard' systems view that is set out in the Mental Health NSF (DoH, 1999a). SSM provides the flexible approach that is more suited to mental health services.

\section{SSM Stage 1 - Background and description of the problem situation}

Surrey and Borders Partnership NHS Trust (SaBPT) was formed on April $1^{\text {st }}$ 2005 , by the merger of three NHS Mental Health Trusts to form one of the country's largest Mental Health and Learning Disability Trusts and the biggest in the South East, outside of London. The three separate Trusts (pre-merger) historically used numerous electronic and manual clinical systems to collect and analyse data for activities such as statistical reports, audits and research, which are still in use and contain inconsistent and incomplete data (CHI, 2004a; 2004b; 2004c). This posed huge challenges for Information and Performance personnel when they compile reports for various statutory bodies and internal teams.

\section{Literature search findings}

A literature review was undertaken structured around the problem, context and methodology and revealed the following themes :

- Lack of access to information/advice hinders successful management of cases (Fakhoury \& Wright 2000, Pollock et al 2004);

- Standards are necessary to measure performance and progress, which promotes improvements (Donabedian 1988, Rea \& Rea 2002);

- There is a need for joint-up care and I.T. systems (Warner \& Hoadley 2004, Rees et al 2004);

- To analyse an organisation holistically, many viewpoints need to be explored and communicated (Wells 1995, Stokes \& Lewin 2003); 
- Soft Systems Methodology (Checkland 1981) accepts there are multiple viewpoints in a given situation and has been employed successfully in the NHS (Summers 2006).

\section{SSM Stage 2 - Construction of the rich pictures}

A 'rich picture' is a pictorial representation of the information obtained at the primary information gathering stage. The responses from the survey questionnaires were analysed to construct visual representations of the processes taking place as perceived by staff in various roles in the Trust in the form of 'rich pictures'. The questionnaire responses were grouped into 'practitioner' and 'nonpractitioner' and analysed from which, two separate rich pictures were constructed. Responses from the survey centred around the following functions within the organisation:

- IM\&T;

- Services;

- Communications network.

These functions formed the main entities in both 'rich pictures' and are represented by 'clouds'.

The following themes emerged from the questionnaires:

- Communication and information flows between services and the IM\&T department;

- Activities that data is currently used for;

- How staff can be encouraged to use data within their services.

The two 'rich pictures' were constructed around these themes and the relationships between them.

Figure 2 shows the 'rich picture' constructed from the responses that practitioners gave in their questionnaires. On closer inspection of this 'rich picture' there were many question marks within the images and on the links between them. This indicates that there were many unknown aspects relating to the role of data.

Figure 3 shows the 'rich picture' constructed from the responses that nonpractitioners gave in their questionnaires. This picture, by comparison, was more organised and there were no open questions. This suggested that non-practitioners have a clearer view of the data that is available to them. The communication and information flows between the various entities or 'clouds' appeared more defined and distinct. 


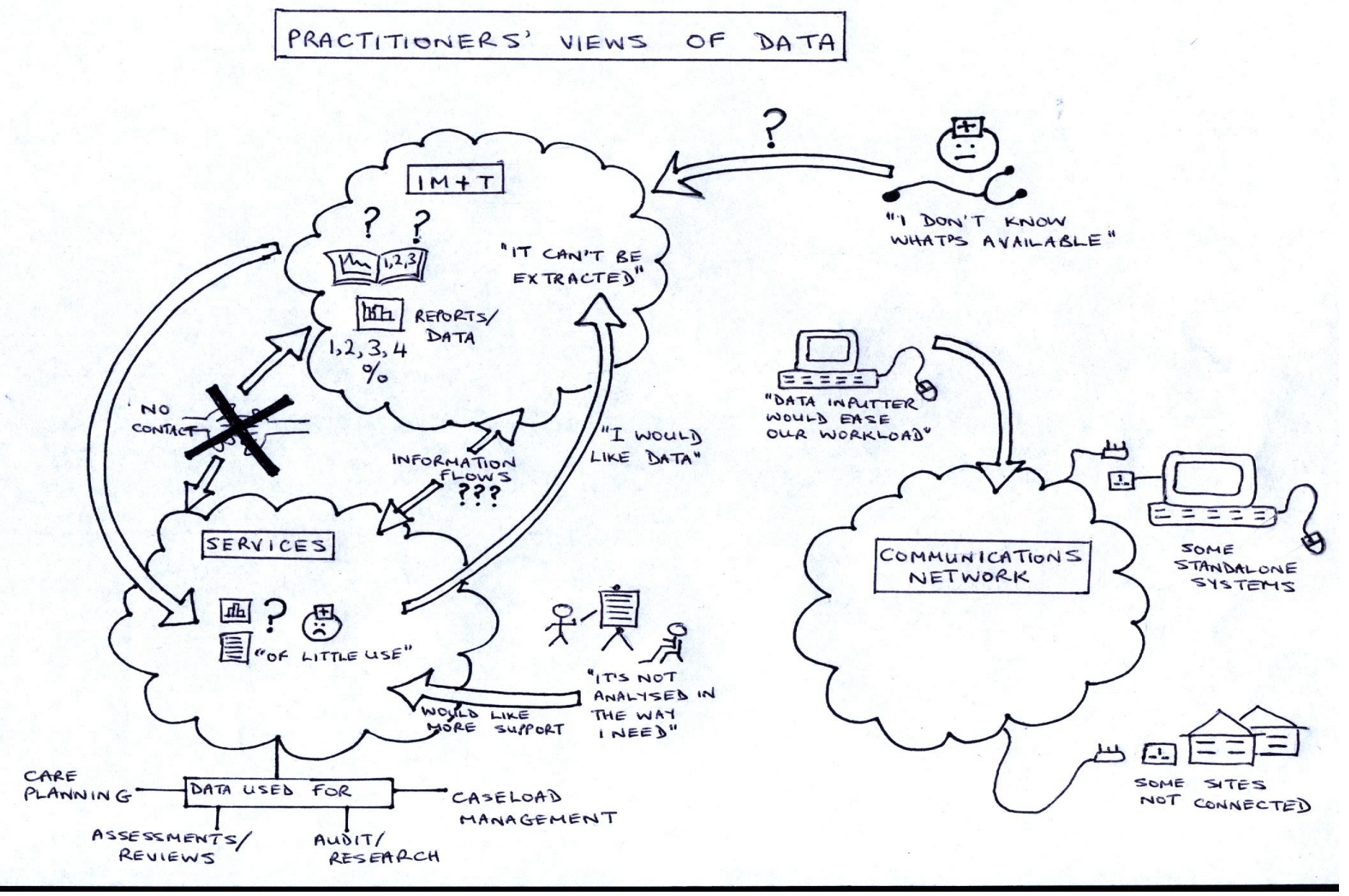

Figure 2. Rich Picture showing practitioners views of data 
Gillies and Patel: IT and the NHS

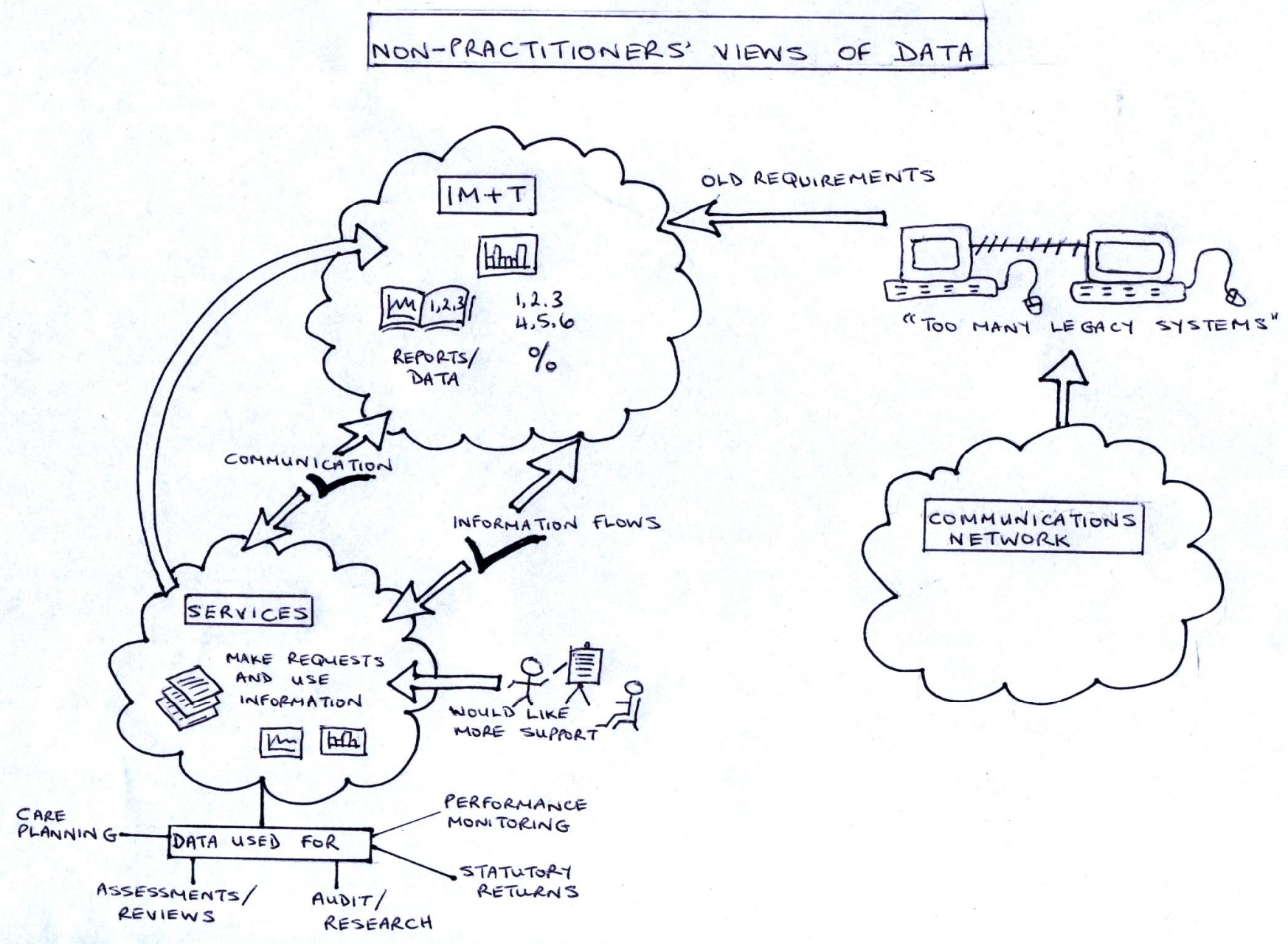

Figure 3. Rich Picture showing non-practitioners views of data. 


\section{SSM Stage 3 - Forming the root definition comprising the CATWOE criteria}

Root Definitions are "concise, tightly constructed descriptions of human activity systems which state what the system is; what is does is then elaborated in a conceptual model which is built on the basis of the definition. Every element in the situation must be reflected in the model derived from it"'( Checkland, 1981).

Smyth and Checkland (1976) concluded that adequate root definitions should have five elements explicitly which are described by the mnemonic CATWOE. The CATWOE that defined this problem situation was defined as follows:

C - Customers: Who receives the benefits of the system?

Practitioners and support staff in the mental health trust

A - Actors: Who implements the system?

Staff in the mental health trust

T - Transformation process: Who implements the system?

Modernising mental health in line with the mental health national service framework

W - Weltansschauug: The world view or value system espoused

Working towards more efficient and cost effective healthcare through better integration

O - Owners: Who controls the system?

Surrey \& Borders Partnership Trust

E - Environmental constraints: What affects the system?

A patient's journey through a multi-agency environment, where currently, information exists in silos and is not joined-up.

The following root definition was formed from the above CATWOE:

"An integrated process, supported by an integrated electronic care record, which is accurate and timely and available to all appropriate staff at the point of care delivery."

The themes that emerged from this definition were:

(1) An integrated process and record;

(2) Accurate and timely;

(3) Available to all appropriate staff;

(4) Point of care.

\section{SSM Stage 4 - Constructing a conceptual model}

Conceptual models are purposeful activity systems that are built according to the world view of the CATWOE. Underwood (1996) stated that these are designed to be the 'ideal' systems to do the desired job. 
The conceptual model links the main findings from the literature review, the survey data, the interview transcripts, and the root definition.

The conceptual model in Figure 4 was formed around the following themes from the root definition to create the 'ideal world' view:

- An integrated process and record;

- Accurate and timely;

- $\quad$ Available to all appropriate staff;

- $\quad$ Point of care;

- $\quad$ Policy \& context.

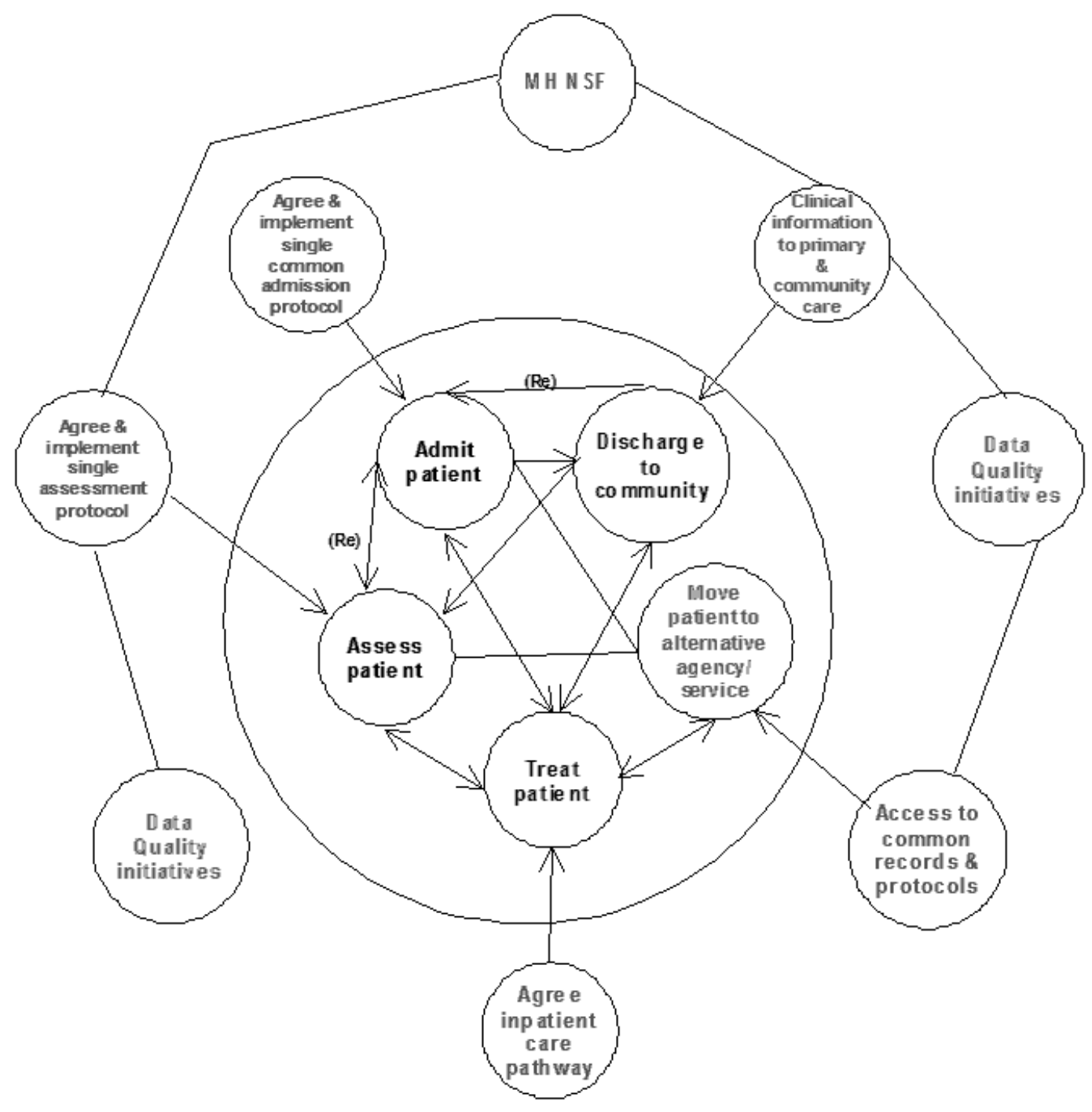

Figure 4: The Conceptual Model 
The inner circle illustrated the links between the activities that occur when a patient/client is admitted to the mental health trust. This was an 'ideal world' view and all the activities should be highly connected and work as a whole as shown in the diagram. In order for the 'inner circle' activities to function effectively, therefore the processes shown outside the 'inner circle' need to be in place. This would present a truly integrated system. The electronic care record, when fully implemented, would be the key enabler allowing all the relevant health and social care agencies to work together.

\section{SSM Stage 5 - A comparison of the conceptual model with the rich pictures}

The conceptual model in Figure 5 displayed the clients' complete journey in and around the mental health trust and shows where the IM\&T initiatives (such as Data quality) relate to this journey. This model provides the strategic input into the activities that are taking place. The arrows represent how information should be flowing between the activities, which are quite distinct.

The 'rich pictures' however show 'snap-shots' of the clients journey in the Trust from the perspectives of two groups of staff. These illustrate that the two groups of staff supporting the client see the flows of information in different ways. These two views are not consistent with each other and provide personal experiences and opinions of how information is being used in practice.

\section{SSM Stage 6 - Visibility of potential solutions}

The new knowledge found from undertaking this research was of a highly localised nature. The following list of recommendations was made to the Trust and the H.I.S.

- The need for integrated systems, which reinforces recommendations from Wanless (2004).

- An integrated information strategy.

- The need for consistent or uniform standards to be in place.

- The role of IM and processes to have an input in the Trusts induction programme.

- Greater support given to clinicians to help them make use of data to support their clinical practice.

- Reinforce the need for greater inter-agency working.

This study exposed local factors, which would not have been highlighted in the hard systems approach. It suggested that the current I.T. implementation was not fit for its intended purpose because it does not take these local factors into account. The knowledge found locally suggests problems with the idea of a 'one size fits all' model, which the national I.T. programme proposes. 


\section{SSM Stage 7 - Plan of action and areas for further research}

The following areas for further research were identified within the case study:

- Data/information gap analysis:

A detailed analysis of the reports which practitioners require would highlight gaps. Results of which could then be fed back to the system development teams through the established communication channels.

- Promoting the use of data for research:

Practitioners are, at present, discouraged from undertaking certain research as they feel it is too time consuming to obtain the information they need. An analysis of the data items which staff would find useful for research and audit could be explored to highlight current gaps in the data provision.

- Study follow-up:

Re-doing the questionnaire used in this study in 2-3 years time would produce different results for a comparative. Parts of the NHS CRS programme will have been implemented and the use of I.T. as a resource will be more prominent than it is at present.

- Data quality:

Currently the patient records, to be migrated onto the new national system will be incomplete, as they will not hold a patient's complete history or care pathway. Additional historical data will be stored and used from a data warehouse (or additional database). This will have implications for data quality and the validity of reports which will be produced.

- The change management process:

The ways in which practitioners and non-practitioners have traditionally worked within the Trust are changing. In order for national programs, such as the CRS to be successful this change process must be well managed. SSM would be a suitable framework to use for such a study as it has been designed to investigate how humans behave when they undertake specific activities.

- Administrative staff as a link between departments:

Administrative staff have been found to be a crucial link between practitioners and Information staff in this study. The I.T skills of such personnel could be harnessed and developed by them working closer with practitioners to help them understand and use data more effectively.

\section{Discussion of the use of Soft systems methodology (SSM)}

The major reason for using SSM in this case study was to provide a method of discerning different views of the problem situation, and to support a piece of action research. 
The different views of the problem situation were clearly highlighted by the rich picture component of the methodology. The later stages also proved useful in defining actions based upon the findings from the study.

The limitation of the methodology is its localised nature. It focuses upon contextual factors within the problem situation. This means that the actual findings of the study are specific to the local problem situation. Therefore, whilst it may be valued by action researchers, it is less valuable as an approach to drawing generalisable conclusions.

In the next section, we shall explicitly consider the ethical legal implications of the problem situation as elucidated by SSM. The ethical and legal implications may be generalisable to other problem situations which can be demonstrated to exhibit the same factors.

\section{Discussion of the ethical and legal implications}

The case study highlighted the problems within the problem situation under scrutiny:

- Disparate and incompatible systems

- A failure to meet clinicians information needs

- A failure to provide information to impact on clinical decision making

- Data quality problems

- Omissions in patient records

Traditionally, these are seen as systems issues and often consequently portrayed as value neutral. However, they have both ethical and legal implications for both management and clinical professionals.

The legal perspective presents some challenges to the current situation as explored within the case study. In terms of the eight data protection principles, the disparate range of systems makes it almost impossible to demonstrate that the legal obligations that data should be fairly and lawfully processed; processed for limited purposes; adequate, relevant and not excessive; accurate and up to date; not kept for longer than is necessary; processed in line with patient rights, and kept secure almost impossible to deliver. Even where it can be delivered, it is impossible to demonstrate compliance. The case study highlighted instances where data was clearly not accurate and timely in terms of the law. Four of the data protection principles can be highlighted as being at risk of being breached:

- Processed for limited purposes. There is no clear overall picture of the purposes for which the data is collected: those collecting the data, generally clinicians, have little knowledge of the range of purposes for which the organisation is collecting the data, and appear to be frustrated that in reality the purposes for which they collect data are less well served than some of the management purposes. 
- Adequate, relevant and not excessive . Clearly the clinicians do not feel that the data collected is sufficient to deliver optimum care, whilst other data is collected which is much less relevant.

- Accurate and up to date . Major issues were highlighted regarding data quality. The fragmented nature of the systems both reduces data integrity and increases the problems of monitoring data integrity

- Not kept for longer than is necessary. The NHS has retention guidelines for ensuring that this requirement is met. However, the current fragmented systems make it difficult to monitor compliance to those guidelines and may also produce conflicting guidelines in a multi-agency approach.

The move to large-scale integrated records systems such as the National care records Service do not of themselves guarantee legal compliance. Indeed the potential consequences of privacy breaches are greater than with small local systems. However, they do offer an opportunity to develop and implement appropriate data protection, appropriate usage, security, and retention strategies and audit trails to demonstrate compliance and trace non-compliant transactions.

The other legal aspect arises from the duty of care to patients. Almost all inquiries into adverse events in the NHS cite a lack of effective information as a contributory factor. Better information systems and more effective clinical decision making arising from the information provided is not only an ethical priority, but offers a genuine reduction in the level of risk of an adverse event leading to legal prosecution arising from a failure in the duty of care.

Ethical issues go far beyond these basic legal requirements. The clinical professionals' obligations are to both minimise harm to patients, staff and in a limited number of cases, the wider public, and to optimise care for patients.

The provision of an integrated care record offers the following potential benefits:

- Better and more complete information to support better clinical decision making and patient care

- Decision support to prevent direct patient harm through adverse events eg prescription errors

- Reduced risk to patients and the public through better risk management of seriously ill patients arising from more complete information

From an ethical perspective this leads to the conclusion that there is an ethical imperative on system developers to provide systems fit for purpose that can deliver these benefits, for managers to implement these systems in a manner that is fit for purpose and for clinicians to make use of the systems when provided to minimize risk and optimize care.

This ethical responsibility is, in reality, a collective responsibility. Much of the broader debate consists of collective finger pointing from different groups. Managers and developers accuse clinicians of "not being engaged". Clinicians 
argue that the systems are not appropriate for their needs and therefore they cannot engage with them. The stakeholder group that is often omitted in such a discussion are the patients around whom everyone's activities should be focused. In order to meet their needs as effectively as possible, it is crucial that the professional groups work together to understand how they can deliver the best possible information in support of the best possible decision making leading to the best possible care.

\section{Conclusions}

The current ethical debate about large scale electronic patient records systems is focused around the ethical and legal implications of threats to patient privacy. This article has sought to establish that this is not the whole story, that the current situation presents ethical and legal challenges, and the move to large scale electronic patient records may not only reduce the risk of privacy breaches and non-compliance with data protection legislation, but offer major benefits in both reducing risk and increasing the positive effects of treatment.

Further, it argues that all professional stakeholders have an ethical and legal requirement to work collectively to use information technology to deliver the best possible information to maximise the benefits, and minimise the risks, for patients.

\section{References}

Bolton C Soft Systems approach to community care, The Health Service Journal $1987,6^{\text {th }}$ August (pp 904-905).

Checkland PB Systems thinking, systems practice 1981, Wiley Chichester, England.

Checkland PB and Scholes J, Soft systems methodology in action, 1990, Wiley, Chicester, England.

Coiera E, Lessons from the NHS National Programme for IT, Medical Journal of Australia, 2007, 186, 1, 3-4.

Commission for Health Improvement, North West Surrey Mental Health Partnership NHS Trust Clinical Governance Review, 2004a, The Stationery Office, London.

Commission for Health Improvement, Surrey Hampshire Borders NHS Trust Clinical Governance Review, 2004b, The Stationery Office, London.

Commission for Health Improvement, Surrey Oaklands NHS Trust Clinical Governance Review, 2004c, The Stationery Office, London.

Department of Health, The National Service Framework for Mental Health Department of Health 1999, The Stationery Office, London.

DOI: $10.2202 / 1941-6008.1094$ 
Donabedian A, The quality of care How can it be assessed? Journal of the American Medical Association, 1988, 260(12), 1743-1748.

Edelstein L The Hippocratic Oath: Text, Translation, and Interpretation, 1943, Johns Hopkins Press, Baltimore.

European Commission, Data Protection Directive, 1995 (95/46/EC).

Fakhoury W, Wright D Communication and information needs of a random sample of community psychiatric nurses in the United Kingdom, Journal of Advanced Nursing 2000, 32(4), 871-880.

Gillies AC The legal and ethical changes in the NHS landscape accompanying the policy shift from paper-based health records to electronic health records, Studies in Ethics, Law and Technology, 2008, vol 2 no 1 art no 4.

Gillies AC and Howard J Final Report CZ2005/IB/SO/03 Development of National Coding Standards within the Czech DRG system, 2008, European Commission.

Goddard J, Alty A and Gillies A, A case study in mental health informatics: barriers and attitudes to information support for integrated care pathways ITIN 2001, September Vol 13,3 (pp 12-13).

House of Commons Committee of Public Accounts, Department of Health: The National Programme for IT in the NHS, Twentieth Report of Session 200607, HC 390, [Incorporating HC 1360-i of Session 2005-06], 2007, The Stationery Office Limited, London.

Lasagna, L "Hippocratic Oath-Modern Version". WGBH Educational Foundation for PBS and NOVA Online. 1964, available online at http://www.pbs.org/wgbh/nova/doctors/oath_modern.html. (checked 09/09)

Macias-Chapula, CA Application of soft systems methodology to develop information flow models at the information system design process A case report In New Worlds in information and documentation (p89) 1992, FID 46 Congress and conference Madrid FID.

Morgan, DL Practical strategies for combining qualitative and quantitative methods: Applications to health research, Qualitative Health Research, 1998;8(3):362-376.

Pollock K, Grime J, Baker E, Mantala K Meeting the information needs of psychiatric inpatients: Staff and patient perspectives Journal of Mental Health, August 2004; 13(4): 389-401.

Rea A and Rea D, Managing performance and performance management, Information strategy and service user involvement, Journal of management in medicine, Vol 16 No1, 2002, pp78-93.

Rees $\mathrm{G}$ et al Joint working in community mental health teams: implementation of an integrated care pathway, Health and Social Care in the Community, 2004, 12(6), pp 527-536. 
Smyth DS and Checkland, PB Using systems approach: The structure of root definitions 1976, Journal of Applied Systems Analysis, 5(1).

Stokes PJ and Lewin D, Information seeking behaviour of nurse teachers in a school of health studies: a soft systems analysis 2003, Nurse Education Today, Volume 24, Issue 1, Pages 47-54.

Summers A Psychological formulations in psychiatric care: staff views on their impact Psychiatric Bulletin, 30(9), September 2006 pp 341-343.

UK National Audit Office, Department of Health: The National Programme for IT in the NHS London: The Stationery Office, 2006: 60.

Underwood, J, Models for change: Soft systems methodology Business Process Transformation, Spring 1996.

Walsham G, Interpreting Information Systems in Organizations, 1993, Wiley, Chichester.

Wanless D Securing our Future: Taking a Long Term View An independent review Available on line at www hm-treasury gov uk/wanless, checked 08/09) 2002, London: The Stationery Office.

Wanless D Securing good health for the whole population ... Good Health for the Whole Population Available on line at www hm-treasury gov uk/wanless, checked 08/09) 2004, London: The Stationery Office.

Warner L, Hoadley A Public Health Information Strategy Improving Information on Mental Health Blocked Pathways Health Service Journal 2004 Feb $12 ; 114(5892): 36$.

Wells, J Discontent without focus? An analysis of nurse management and activity on a psychiatric in-patient facility using a 'soft systems approach' Journal of Advanced Nursing Vol 21(2), February 1995, pp214-22.

Williams J National Programme for IT: the $£ 30$ billion question, British Journal of General Practice 2005, 1; 55(514): 340-342 PMCID: PMC1463155. 